\title{
Research
}

\section{Spatial Trade-Offs between Wind Power Production and Bird Collision Avoidance in Agricultural Landscapes}

\author{
Marcus Eichhorn $^{1}$ and Martin Drechsler ${ }^{1}$
}

\begin{abstract}
The expansion of renewable energy production is seen as an appropriate way to mitigate climate change. Renewable energies are not free of negative external effects on humans and the natural environment. We analyzed the conflict between wind power production and bird protection through the example of one of the most sensitive species, the red kite (Milvus milvus) in West Saxony, Germany. We investigated a large number of potential land use scenarios, defined by whether or not each potential site contained a wind turbine (WT). Based on meteorological and ornithological data, we evaluated the land use scenarios for their annual energy supply and impact on the red kite. We identified the efficient land use scenarios that maximized energy supply for a given ecological impact. Within the scope of our analysis, the current allocation of WTs in the study region was considered inefficient. The set of efficient scenarios allowed us to draw conclusions on the trade-offs involved. We developed an indicator that measures the severity of the conflict between wind power production and bird protection. Increasing the minimum distance of WTs to settlements beyond the legal requirements in order to minimize the impact on humans further intensifies the conflict. Our results can support planning authorities in their development of longterm regional plans by identifying areas that are most suitable for wind power production from an integrated point of view.
\end{abstract}

Key Words: bird protection; efficiency frontier; land use optimization; spatial allocation; trade-off; wind power

\section{INTRODUCTION}

Innovative technologies are developed to reduce emissions and slow down global warming in times of climate change caused largely by $\mathrm{CO}_{2}$ emissions from human-related energy production, population growth, and consumption patterns. One of these $\mathrm{CO}_{2}$ neutral energy generation technologies is wind power production. Wind is a renewable energy source that can be used nearly all over the world, and is limited only by atmospheric conditions and the capacity and spatial extent of electricity networks. Compared to other types of renewable energy production, the use of wind energy is one of the economically most efficient (BMU 2008).

But like most human land use activities, wind power production is not free of environmental impacts (Bishop 2002, Langston and Pullan 2003, Möller 2006, Bright et al. 2008, Carmen et al. 2009, Tsoutsos 2009). On the one hand, humans are impacted through sound emissions, shadow emissions, and the disturbance of the scenic value of the landscape. On the other hand, nature is impacted through loss of habitat, disturbance and displacement of birds, and increased collision risk for bats and birds, particularly for raptors.

Commercial wind power production started in the 1970s in California. At that time there was little or no experience with the environmental impact of wind turbines (hereafter referred to as WTs), so site selection was based mainly on energetic considerations. Later research on the impact of WTs on birds in the USA indicated that these impacts can be substantial (Hunt 2002, Lowitz 2008). Most bird kills were recorded at Altamont Pass, where about 4900 wind turbines are installed. An estimated 880 1300 birds of prey were killed annually. This included up to 116 Golden Eagles, a federally protected species, 300 Red-tailed Hawks, 380 Burrowing Owls, and hundreds of other raptors, 
including kestrels, falcons, vultures, and other owl species (CBD 2009).

In recent years, bats have also been identified as being affected by WTs. An extensive review of studies about the impacts of WTs on birds and bats is provided by Hötker et al. (2006). Despite this knowledge about the environmental impacts of WTs, the integrated analysis of the conflict between wind power production and bird protection is still a challenge. Important questions are how severe these conflicts are, and how the severity of the conflicts depends on external factors such as legal requirements and social concerns.

A conflict between wind power production and bird conservation occurs if areas occupied by the birds concerned are suitable for wind power production. We present a multi-criteria approach for the analysis of this conflict which integrates expert knowledge about the ecological impacts of WTs (e.g., Reichenbach et al. 2004) with information about the energy productivity of individual sites in a spatially explicit optimization framework. For other applications of multi-criteria analysis of environmental problems, see Brown and Cobera (2003), Kiker et al. (2005), Huth et al. (2005), and Moffett and Sarkar (2006). In our approach, the physically suitable sites for wind power production are identified and land use scenarios are defined by deciding whether each potential site is used for wind power production or not. We determine the potential energy productivity and the ecological impact for each site. Based on these data, all Pareto-optimal land use scenarios (the so-called efficiency frontier: e.g., Calkin et al. 2002, Polasky et al. 2008, Ehsan et al. 2009) are determined where a scenario A is Pareto-optimal if there is no other scenario that outperforms $\mathrm{A}$ in at least one criterion (in the present case: lead to higher total wind power production) without underperforming in any other criterion (in the present case: lead to a higher impact on the focal bird species). The shape of the efficiency frontier allows us to assess the severity of the conflict between wind power production and bird protection in the region.

Bird protection and energy production are not the only relevant criteria for the allocation of WTs. In an economic valuation study, Meyerhoff et al. (2008) found that the public is highly concerned about the distance of WTs to settlements; larger distances are significantly preferred to smaller distances. This additional constraint is likely to affect the trade-off between wind power production and bird protection. We apply our approach to evaluate the trade-off between wind power production and bird protection in a German planning region and investigate how this trade-off is affected by the consideration of the distance between WTs and settlements.

\section{METHODS}

\section{Study region}

The study region comprises the area of the planning region West Saxony, which is a part of the Free State of Saxony. It has about one million residents and an area of approximately $4300 \mathrm{~km}^{2}$ (Fig. 1).

We chose this area for various reasons. On the one hand, West Saxony has a relatively low amount of installed wind power capacity compared to other regions. In 2007 there were 221 wind turbines with a nominal capacity of $235 \mathrm{MW}$ (megawatts). For comparison, the planning region Anhalt-BitterfeldWittenberg, bordering West Saxony to the northeast, has an almost similar area $\left(3627 \mathrm{~km}^{2}\right)$ but 445 WT with 627 MW installed capacity (RPG ABW 2007). Since the West Saxony region has a high proportion of open areas (only $16 \%$ of the area is covered by forest [RPV WS 2008]) and since open landscapes imply a high ground level wind speed (Wizelius 2007), conditions for the further development of wind power in the region are promising.

On the other hand, the region is part of the world's core habitat of the endangered red kite (Milvus milvus) (Glutz von Blotzheim 1989, Mebs and Schmidt 2006, BirdLife International 2009). Approximately $50 \%$ of the world's red kite population lives in Germany, nearly $10 \%$ of which is found in Saxony. The red kite, a synanthropic species, uses anthropogenically used open rural areas for foraging and (partly) for breeding (Nachtigall 2008). It has no natural enemies, except for human beings, so avoidance behavior has not evolved in the species (Mammen and Dürr 2006, Dürr 2008). Since red kites and WTs "use" very similar landscapes, we expect a substantial conflict between prospective wind power production and red kite protection in our study region, and measure the ecological impact of a WT by its predicted impact on the local red kite population. Other biodiversity issues are considered in the definition of the 
Fig. 1. The planning region West Saxony.

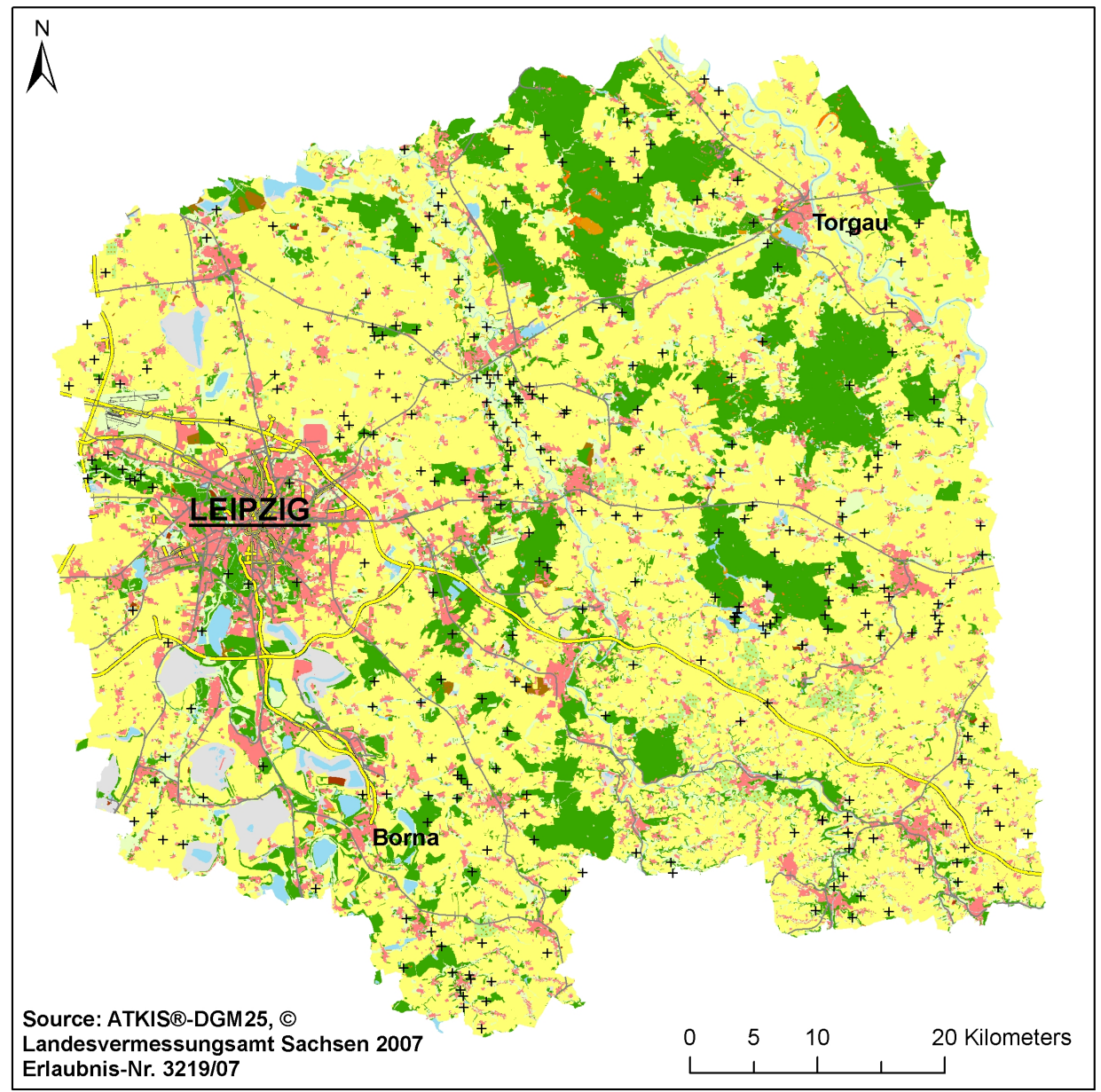

Land use/ Land cover
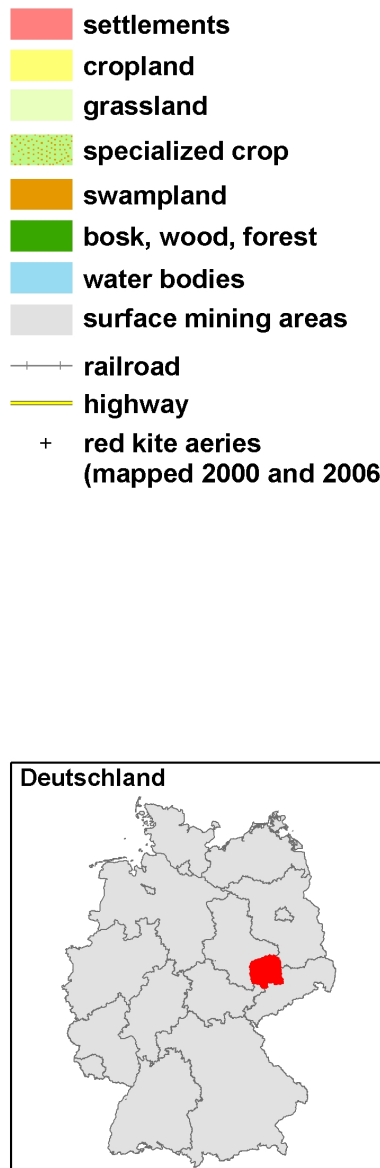

suitability space (Methods: Determination of the suitability space).

\section{Data sources}

We used real land use/land cover data available as vector data provided by the public survey for Geo Base Information and Measurement Saxony to identify suitable areas for the construction of WTs. The calculation of the amount of wind power produced was based on the frequency distribution of wind speeds, obtained with a horizontal resolution of one-by-one kilometer from the German National Weather Service, and parameters specific to the type of WT, obtained from
ENERCON (2008). The determination of the impacts of the WT on the local red kite population was based on the spatial locations of known aeries in the study region. These locations were mapped in 2000 and 2006 by volunteer ornithologists and were provided by the Saxon State Office for Environment and Geology.

\section{Determination of the suitability space}

The suitability space comprises those parts of the landscape that are physically and legally qualified for the allocation of WTs. To delineate these parts of the landscape, we began by identifying all areas in the region with land cover types physically 
suitable for the construction of WTs. These land cover types include all open areas of the landscape, i.e., cropland, grassland/pasture, heath, scrubland, vegetation-free areas, and acclivity/reclaimed land. Then we removed all areas that are not legally qualified for the construction of WTs according to LANUV NRW (2002), TA Lärm (1998), BfN (2008), and several laws, such as article 9 of FStrGBundesfernstraßengesetz, article 24 of SächsStrGSächsisches Straßengesetz, and article 3 of LEisenbG-Landeseisenbahngesetz).

To allocate WTs within the suitability space, we used a Monte Carlo Simulation, programmed by Dr. Ralf Guckel, to determine potential sites for WTs. The program fills the suitability space with the maximum possible number of potential sites while considering minimum distances between individual sites. These minimum distances are required to avoid the wind park effect, which denotes the reduction of the energy output of a WT located at the lee side of other WTs (Wizelius 2007: pp. 234236). For the chosen type of WT, the minimum distance to avoid the wind park effect amounts to $410 \mathrm{~m}$, which is five times the WT's rotor diameter. We obtained a number of $N=1022$ potential WT sites.

\section{Multi-criteria evaluation}

To analyze the conflict between wind power production and red kite protection, the policy criteria needed to be defined as measurable quantities, and all land use scenarios had to be evaluated by these quantities. To generate a land use scenario, we decided whether or not each potential WT site within the suitability space should contain a WT. For simplicity's sake, we assumed that all WTs were of the same type and had a state-of-theart wind turbine with a hub height of $80 \mathrm{~m}$, a rotor diameter of $82 \mathrm{~m}$, and a nominal power of $2 \mathrm{MW}$. One land use scenario, for example, may be to construct a WT on site 1 and no WT on the others. Another scenario may be to construct a WT on site 2 and none on the others. A third scenario may be to construct a WT on each of sites 1 and 2 and none on the others, etc. With $N=1022$ sites available, there is a number of $2^{N}$ of these combinations, i.e., $2^{N}$ different land use scenarios.

\section{Energy production}

To calculate the energy production for the selected WT technology at a given site, we needed the frequency distribution of the wind speed at $80 \mathrm{~m}$ above ground level and the power curve for the selected WT technology, which tells how much electrical power the WT will produce at a given wind speed.

The frequency distribution of the wind speed $v$ is suitably described by a Weibull distribution (Hau 2006: pp. 509-514, Wizelius 2007: pp. 49-50), which is characterized by a scale and a shape parameter (denoted as $A$ and $k$ ):

$$
f\left(v_{m}\right)=k / A\left(v_{m} / A\right)^{(k-1)} \exp \left\{-\left(v_{m} / A\right)^{k}\right\}
$$

(Fig. 2 left panel). Since we are considering a discrete wind speed distribution, $v_{m}$ in Eq. 1 denotes the wind speed in the $m^{\text {th }}$ interval. The power $P\left(v_{m}\right)$ generated by the chosen WT technology for a given wind speed $v_{m}$ is shown in Fig. 2 (right panel). The expected energy produced by the WT in one year $\left(E_{a}\right)$ is therefore the sum of all values $P\left(v_{m}\right)$ weighted by the frequency $f\left(v_{m}\right)$ by which the wind speed $v_{m}$ is observed at the site under consideration, multiplied by the expected number of hours per year $\left(t_{a}=8760 \mathrm{~h}\right)$ :

$$
E_{a}=t_{a} \sum_{m=0}^{m_{\max }} f\left(v_{m}\right) P\left(v_{m}\right)
$$

Here $m_{\max }$ represents the upper bound of the wind speed range within which the WT operates (Fig. 2, right panel). For each site within the suitability space, we obtained the values for the parameters $A$ and $k$ from the German National Weather Service (Methods: Data sources), and using Eqs. 1 and 2, calculated the annual energy production levels. To evaluate land use scenarios with several WTs, we determined the annual energy production of each WT according to Eq. 2 and took the sum of these values. For simplicity's sake, we have omitted the term "annual" so that energy production always refers to the amount of energy produced per year.

\section{Red kite protection}

Most red kite collisions with WTs occur during foraging flights in the breeding season. Depending 
Fig. 2. Calculation of the produced wind power for a particular site. Left panel: example of a wind speed frequency distribution; right panel: power curve for the selected technology option (ENERCON 2008).
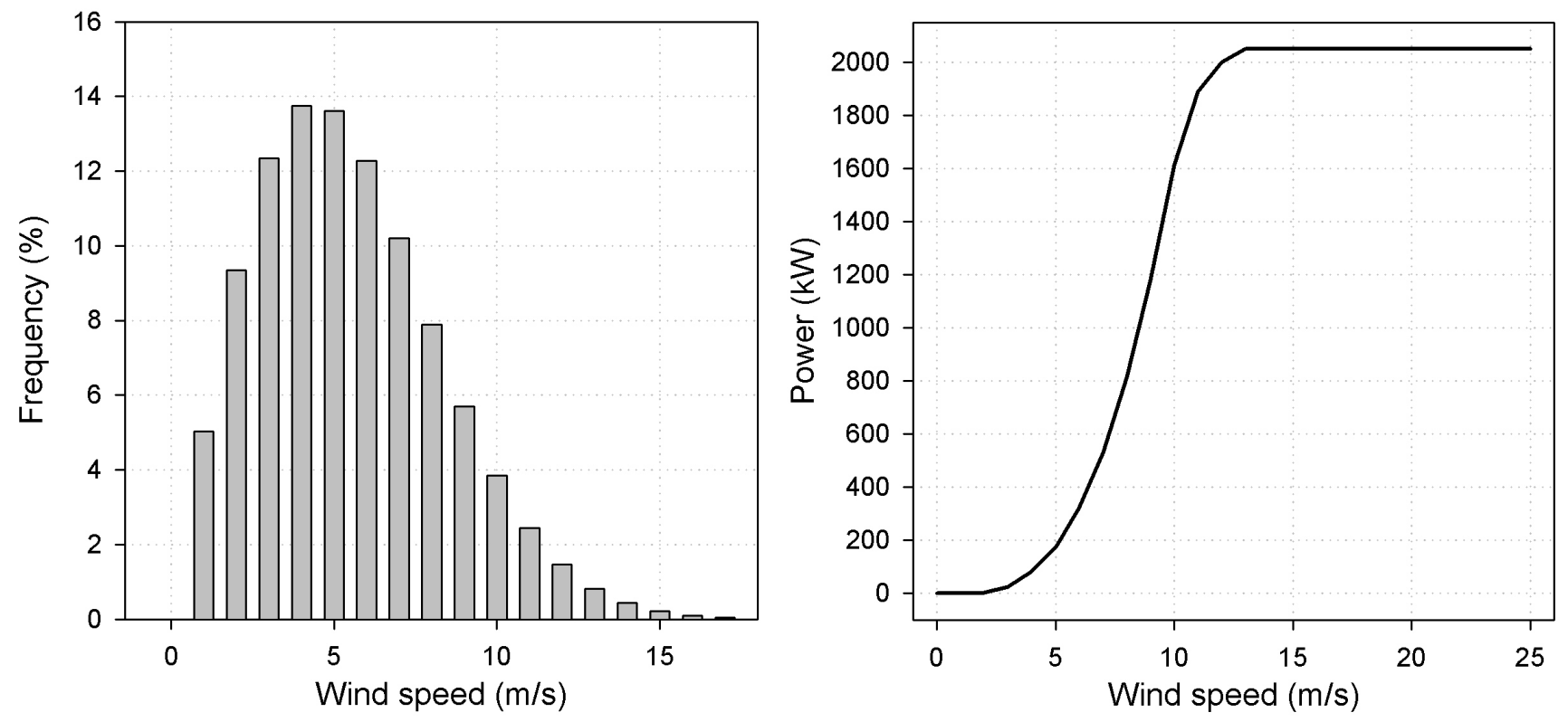

on habitat quality, defined by frequency and availability of prey, these flights occur at different distances to the aerie. Based on information received from Nachtigall (2008) and other experts, we modelled the likelihood, $L$, of observing a red kite at a distance $d$ from its aerie using Eq. 3:

$$
L(d)=\exp \left\{-(d / k)^{2}\right\}
$$

Since the bird is most frequently (about $90 \%$ of the time) observed at distances less than $3000 \mathrm{~m}$ from the aerie (see Nachtigall 2008: pp. 61-62), we set $k$ $=3000 \mathrm{~m}$ (the results are not very sensitive to moderate changes in $k$ ).

The probability of a red kite colliding with a WT is proportional to the likelihood of the bird occupying the same physical space as the WT. Therefore, given that $L(d)$ is the likelihood of a bird being observed at a distance $d$ from the bird's aerie, the probability of the bird colliding with a WT located at distance $d$ from the aerie is proportional to $L(d)$. In other words, a WT at distance $d$ from a red kite's aerie has an adverse impact of $\alpha \mathrm{L}(d)$ where $\alpha$ is some proportionality factor. Assuming there is $M>1$ aerie within our study region, the total impact, $I$, of a WT at a particular site on all aeries is the sum of the impacts obtained for each aerie:

$$
I=\alpha \sum_{j=1}^{M} L(d j)
$$

where $d_{j}$ is the distance of the WT to the $j^{\text {th }}$ aerie. Since we are interested only in the relative suitability of the different sites, we can set the proportionality factor $\alpha$ to 1 . Varying $\alpha$ changes only the scale of the total impact in the region (the horizontal axis in Fig. 5), and the choice of $\alpha=1$ implies no loss of generality within the scope of the present study. 
To evaluate land use scenarios with several potential WT sites, we determined their individual impacts according to Eq. 4 and took the sum of these impacts. This sum, henceforth termed "ecological impact", is related to the mortality of the birds. It has an arbitrary scale, which, however, is sufficient within the scope of this study. WTs at the boundary of the study region will also have an impact on aeries close to, but outside, the study region. Since no data about these aeries were available, we generated a $13 \mathrm{~km}$ wide buffer around the study region. Aeries are randomly distributed within this buffer at the same density observed within the study region. To remove sampling stochasticity, we sampled 10 different buffers, analyzed our allocation problem for each buffer replicate, and took the average of the results.

\section{Analysis of the trade-offs}

Each land use scenario can be plotted by its energy production level and ecological impact. A higher energy production is preferred to a lower one and a lower impact is preferred to a higher one. To analyze the trade-off between energy production and ecological impact, we determined the Paretooptimal land use scenarios and ranked the potential WT sites by their ratio of energy production and ecological impact. The first Pareto-optimal scenario, therefore, was obtained by allocating one WT to the site with the highest ratio and no WT to all other scenarios. The next Pareto-optimal scenario was obtained by allocating a WT to each of the two sites with the highest ratios and no WT to all other sites. We proceeded by adding sites one by one with decreasing ratios until all $N$ sites of the suitability space were filled with WTs. The $N$ land use scenarios that we obtained through this procedure were all Pareto-optimal.

This procedure worked because (i) we considered only two criteria, (ii) the criteria were additive so that the energy production and impact of two sites was the sum of the respective values for the individual sites, and (iii) the number of potential sites was very large and each site contributed only marginally to the criteria. With conditions (i) and (ii), our optimization problem qualified as a socalled knapsack problem (e.g., Hajkowicz et al. 2008) in which a number of items was selected under a budget constraint so that for a given budget the sum of the items' benefits was maximized. If it were possible to select only fractions of items, we would be confronted with a fractional knapsack problem, which is solved by selecting the items in decreasing order of benefit-cost ratio, with the addendum that if the selection of the last item violated the budget constraint, only a corresponding fraction of the last item is selected (e.g., Dantzig 1963). Although WTs cannot be selected in fractions, due to condition (iii) the associated error was negligible and our procedure of selecting WTs in decreasing order of energy-impact ratio was identical to the approach developed by Dantzig (1963) and correctly identified the Pareto-optimal land use scenarios.

If one or more of conditions (i)-(iii) are not fulfilled, linear programming (e.g., Schrijver 1998, Öhman and Eriksson 2002, Meyer and Grabaum 2008, Ehsan et al. 2009) or heuristics such as tabu search (e.g., Bettinger et al. 2007) or simulated annealing (e.g., Kirkpatrick et al. 1983, Öhman and Eriksson 2002, Westphal et al. 2007, Bettinger et al. 2008) need to be used.

Plotting the Pareto-optimal scenarios by their performances in the two criteria yields a line called the efficiency frontier (e.g., Polasky et al. 2008). The shape of this line represents the nature of the decision conflict. Below we show that the area under the efficiency frontier indicates the severity of the decision conflict.

As stated in the Introduction, another relevant issue is the minimum distance $D$ of WTs to settlements. We expected that varying this minimum distance would affect the shape of the efficiency frontier. Therefore, we generated an efficiency frontier for different levels of $D$. Alternatively, we may assume that the political will exists to produce certain amounts of energy in the region. Then it is of interest to discuss the trade-off between $D$ and the impact of the WT on the red kite for a given energy level. We investigated this trade-off for different levels of energy production.

\section{RESULTS}

\section{Performances of the wind turbine sites}

Fig. 3 shows the energy that can be produced per year at each potential WT site. The sites with the highest productivity are in the northwestern and eastern parts of the study region. Fig. 4 shows the impact that a WT would impose on the local red kite population for each potential WT site. The highest impacts would be imposed at sites in the north and the east. Combining Figs. 3 and 4 shows an overlap 
of the regions that are both ecologically sensitive and suitable for wind power production, implying there is a conflict between red kite protection and wind power production.

\section{Trade-off between ecological impact value and energy output}

Fig. 5 illustrates the efficiency frontier for our study region. Each point on the curve represents a land use scenario. As described in Methods: Analysis of the trade-offs, we obtained the points by gradually filling the region with WTs. At the lower left point of the curve, the locations that have the highest energy output ("gain") for a given ecological impact are selected ("cost"). It is sufficient to use only these optimal locations if only a small amount of energy is to be produced. As a consequence, relatively a lot of wind power can be produced with relatively little ecological impact, implying a high slope of the efficiency frontier. In order to produce a larger amount of energy in the region, increasingly more WTs have to be installed at locations with worse gain-cost ratios, implying a gradually declining slope of the efficiency frontier until the suitability space is completely filled with WTs. At this point, both the ecological impact and the energy production are maximal (end point of the curve, upper right corner of Fig. 5).

The resulting curve is termed an efficiency frontier (e.g., Polasky et al. 2008). Its positive slope reveals that any increase in the energy output can be achieved only at a higher ecological impact. At the lower left corner, the ecological impact is small as is the amount of energy produced, while at the upper right corner, energy output is at a maximum as is the ecological impact. The area under the curve can be used to measure the severity of the decision conflict. To understand this, consider the dashed line in Fig. 6, which represents a fictitious efficiency frontier. About $85 \%$ of the maximum energy output ( 2500 out of $3000 \mathrm{GWh}$ ) can be produced at only $20 \%$ of the maximum ecological impact (400 out of 1900 impact units). Conversely, with the dotted line, representing another fictitious efficiency frontier that might apply in the presence of a more complex, non-additive ecological impact function, the same energy output can be achieved only at more than $95 \%$ of the maximum ecological impact. Obviously, the decision conflict represented by the dotted line is much more severe than that represented by the dashed line. In fact, no conflict would exist in the extreme case where the maximum energy output could be obtained at zero ecological impact, while a most severe conflict would exist if any non-zero energy output could be obtained only at maximum ecological impact.

A geometric quantity that characterizes these different shapes of the efficiency frontiers is the area under the curve (AUC) (shaded area in Fig. 6). Curves with a large (small) AUC are associated with a weak (severe) decision conflict. Denoting the maximum energy output as $E_{\max }$ and the maximum ecological impact as $I_{\max }$, the conflict severity, $S$, is defined in Eq. 5 as

$$
S=1-\frac{A U C}{E_{\max } I_{\max }}
$$

AUC ranges from zero (most severe conflict) to $E_{\text {max }}$ $I_{\max }$ (no conflict); therefore, $S$ ranges from zero (no conflict) to one (most severe conflict). The conflict severity in our WT allocation problem (solid line in Figs. 5 and 6) is about 0.35 .

In addition to the shape of the efficiency frontier and the associated severity of the conflict, another relevant question is how the current situation relates to the efficiency frontier. The current situation is characterized by a number of 221 installed WTs supplying an energy output of 345 gigawatt hours (GWh) and imposing an ecological impact of 401 (point $\mathrm{i}$ in Fig. 5). Point $\mathrm{i}$ is located below the efficiency frontier, which means that under our chosen constraints, the current situation is not Pareto-efficient. In Fig. 5, points i, j, and k span the space of possible Pareto-efficiency gains. On the one extreme, the energy output could be increased without changing the ecological impact. Compared to the current level of $345 \mathrm{GWh}$, the energy production would be quadrupled (point $\mathrm{j}$ in Fig. 5). This shift would involve reallocating, repowering (replacing older and underperforming turbines with new ones that have higher performance levels), and installing additional WTs. On the other extreme, the ecological impact could be reduced without changing the level of energy production (point $\mathrm{k}$ in Fig. 5). At point k, the same amount of energy is produced with nearly half the number of WTs. In the scenario associated with point $\mathrm{k}$, the WTs tend to have greater distances to the aeries than in the 
Fig. 3. Energy production map. Each dot represents a potential wind turbine site. Color represents the amount of energy that can be produced per year at the site. Black represents settlements.

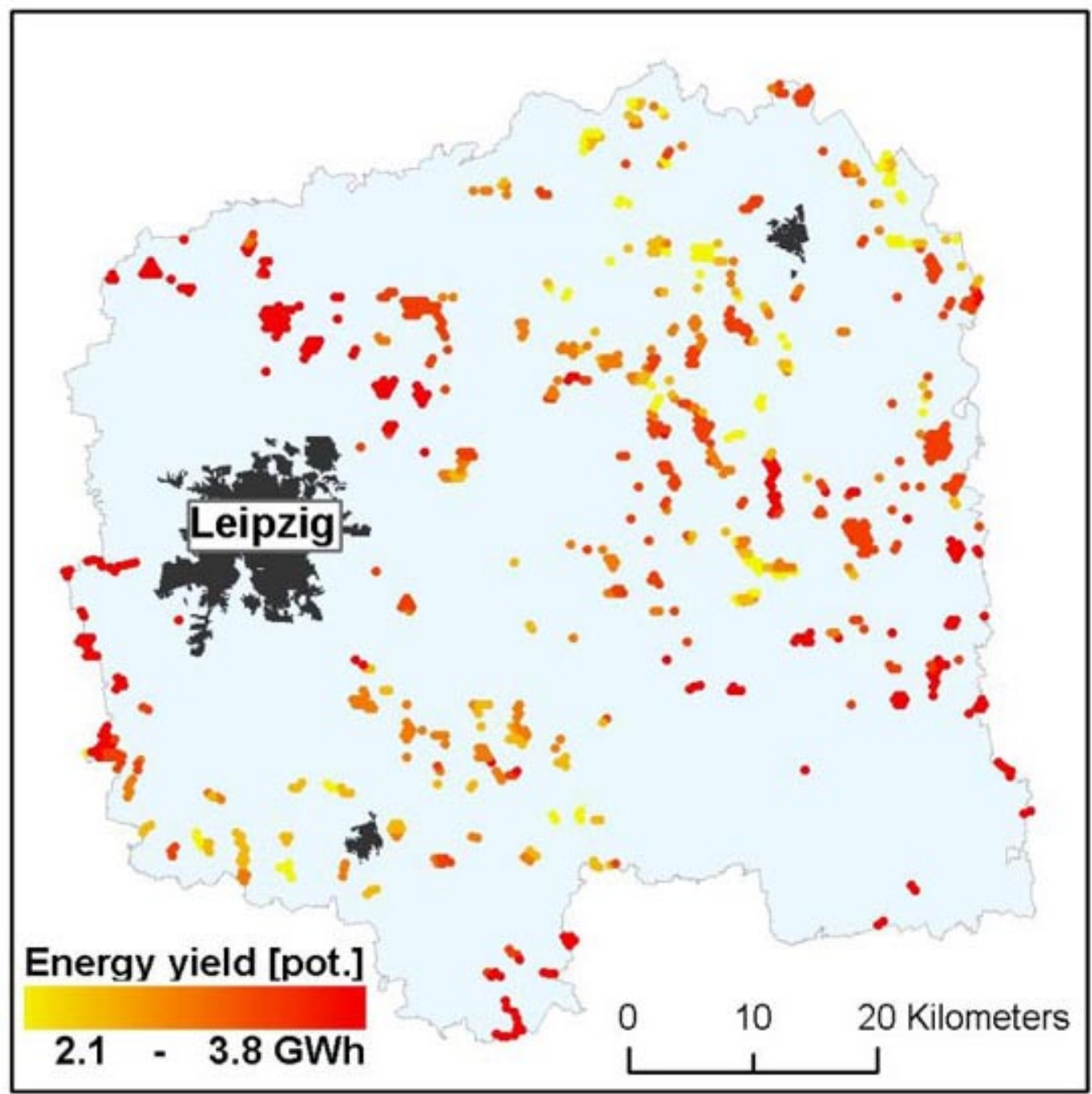

scenario associated with point $\mathrm{j}$, resulting in a much smaller ecological impact.

\section{Effects of incorporating social constraints}

Another important criterion is the minimum distance of WTs to settlements. In Fig. 5, this distance was set at $800 \mathrm{~m}$ based on legal constraints (Methods: Determination of the suitability space). Fig. 7 shows how the efficiency frontier changes if the settlement distance is increased. First, the maximum possible energy production and the associated maximum ecological impact are reduced because fewer sites are available for WTs. Raising the settlement distance from $800 \mathrm{~m}$ to $1000 \mathrm{~m}$, for example, reduces the maximum energy production from about $3000 \mathrm{GWh}$ to about $1000 \mathrm{GWh}$. At a settlement distance of more than $1200 \mathrm{~m}$, even the current level of $345 \mathrm{GWh}$ cannot be maintained. Second, an increase in the settlement distance aggravates the trade-off between red kite protection and energy production. At a settlement distance of $800 \mathrm{~m}$, about $2100 \mathrm{GWh}$ can be produced at an ecological impact of 800 units; at a settlement 
Fig. 4. Impact map. Each dot represents a potential wind turbine site. Colors represent the ecological impact of a wind turbine at the site. Black represents settlements.

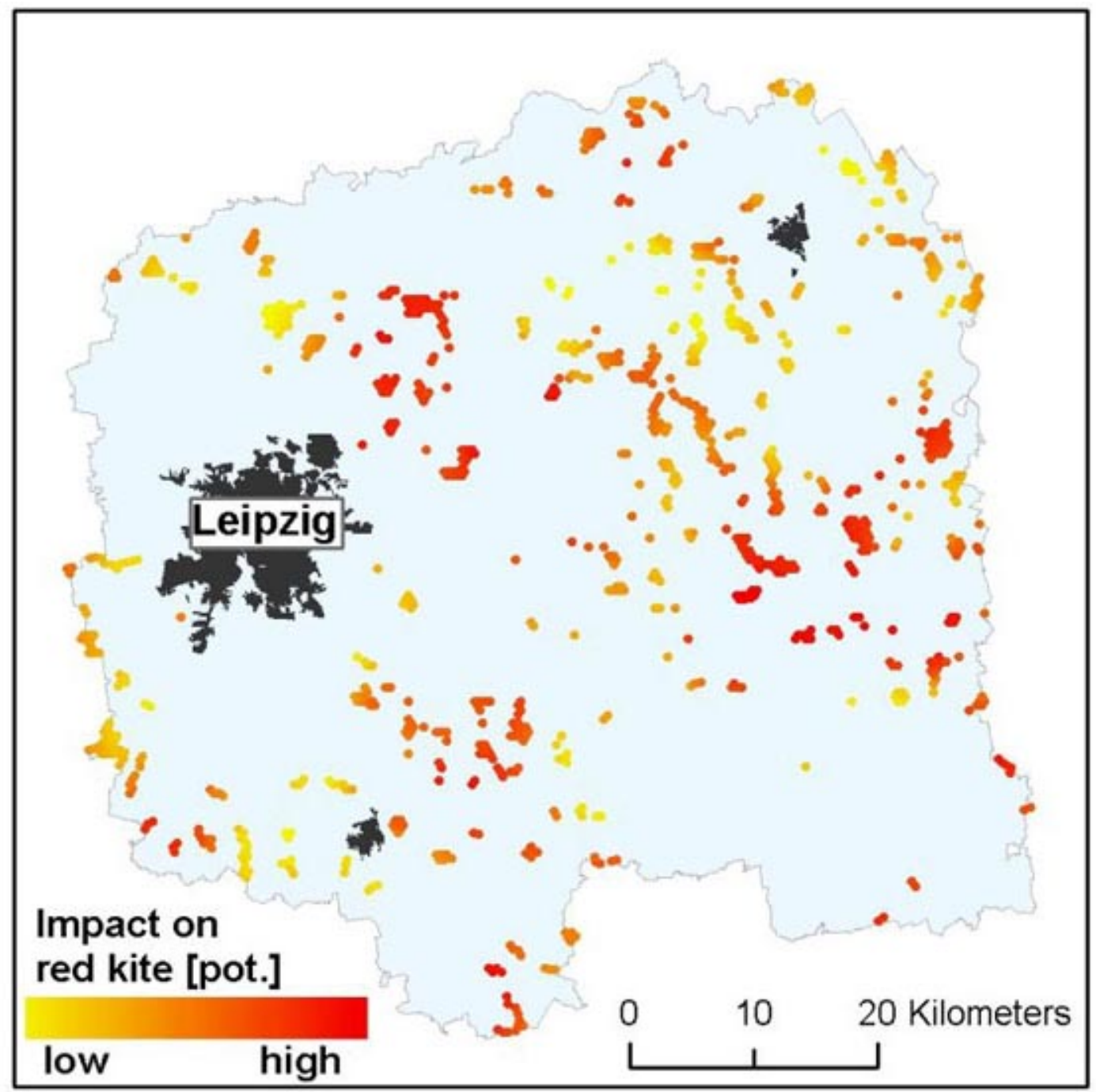

distance of $900 \mathrm{~m}(1000 \mathrm{~m})$, the energy production at the same ecological impact drops to $1600 \mathrm{GWh}$ $(1200 \mathrm{GWh})$. The reason is that not only does the total number of suitable sites decline with increasing settlement distance, but so does the number of sites where energy can be produced with little ecological impact.

This indicates that a trade-off exists not only between energy production and red kite protection but also between these two criteria and settlement distance. Fig. 8 depicts the trade-off between the ecological impact and the settlement distance at given levels of energy production. An increased settlement distance is associated with an increased ecological impact because at large settlement distances the number of available WT sites is small and sites close to red kite aeries have to be selected to meet the given energy production level: a classic trade-off between the well-being of humans (absence of WTs in their vicinity) and the survival demands of species. The trade-off between settlement distance and ecological impact is aggravated if more energy is produced (Fig. 8). At 
Fig. 5. Efficiency frontier. Energy production versus ecological impact. Solid line: as calculated for the study region. Point i represents the current situation in the study region; the other two points represent two possible ways of increasing efficiency (see Results: Trade-off).

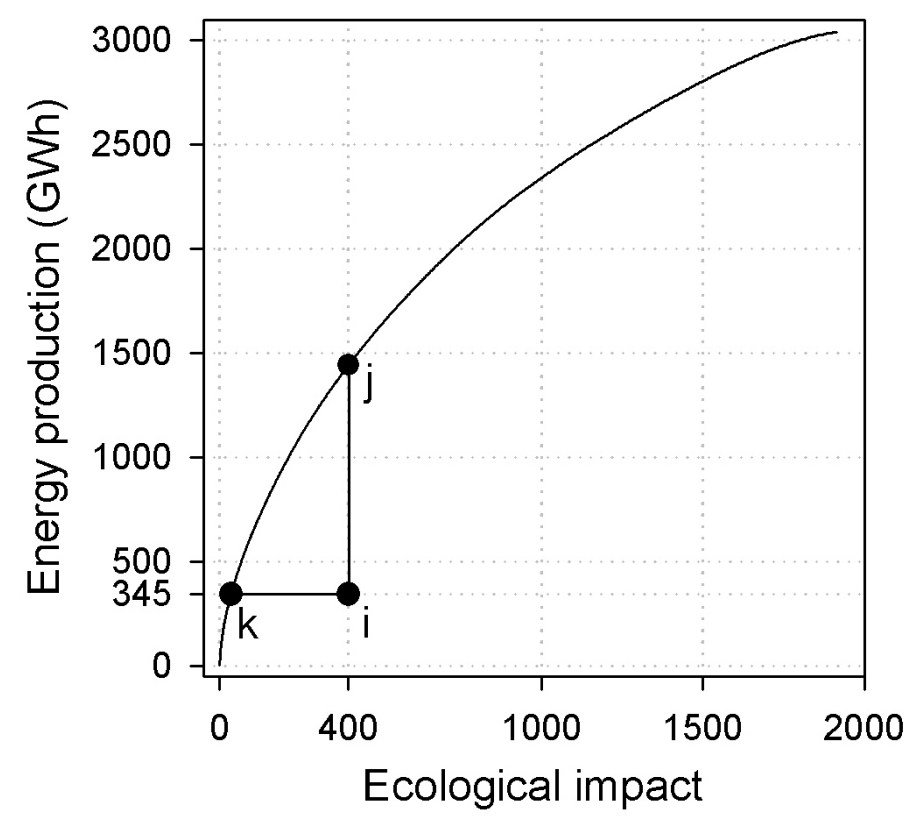

the current energy production level of $345 \mathrm{GWh}$, an increase in the settlement distance of $100 \mathrm{~m}$ increases the ecological impact by about 25 units; at a doubled energy production level of $690 \mathrm{GWh}$, the ecological impact increases by about 50 units per $100 \mathrm{~m}$ settlement distance.

\section{DISCUSSION}

Since space is generally limited, it is important to allocate WTs efficiently. We employed the concept of Pareto-optimality in order to identify efficient allocation scenarios with regards to wind power production, red kite protection, and disturbance of humans in West Saxony, Germany. For a given minimum distance of WTs to settlements, the Pareto-optimal scenarios form a line (efficiency frontier) in the space spanned by the two criteria "energy production" and "ecological impact". The area under this line (AUC) can be used to measure the severity of the conflict between the criteria. A large AUC means that the land use scenarios are close to the "ideal point" where both criteria are optimally fulfilled. According to Polasky et al. (2008), for example, protecting all relevant species in the Willamette Basin, Oregon would cost about US\$27 billion. But in scenario D of Polasky et al. (2008), 98\% of these species can already be protected for only about US\$2 billion, meaning that scenario $\mathrm{D}$ is close to the ideal point where all species would be protected at zero cost. In Eq. 5, we proposed a measure of conflict severity, $S$, that ranges from zero (no conflict) to one (most severe conflict). The conflict severity in Polasky et al. (2008) is about $S=0.15$; in this study, $S=0.35$. This value is considerably higher than those in many other environmental studies, such as Calkin et al. (2002), Nalle et al. (2004), Polasky et al. (2008), and Bladt et al. (2009). As we could demonstrate, additional constraints, such as an increased minimum distance of WTs to settlements in our study, may further increase the severity of a conflict. 
Fig. 6. Efficiency frontier. Energy production versus ecological impact. The solid line is as calculated for the study region, dashed and dotted lines are two fictitious efficiency frontiers. Shaded area: the area (AUC) under the solid efficiency frontier.

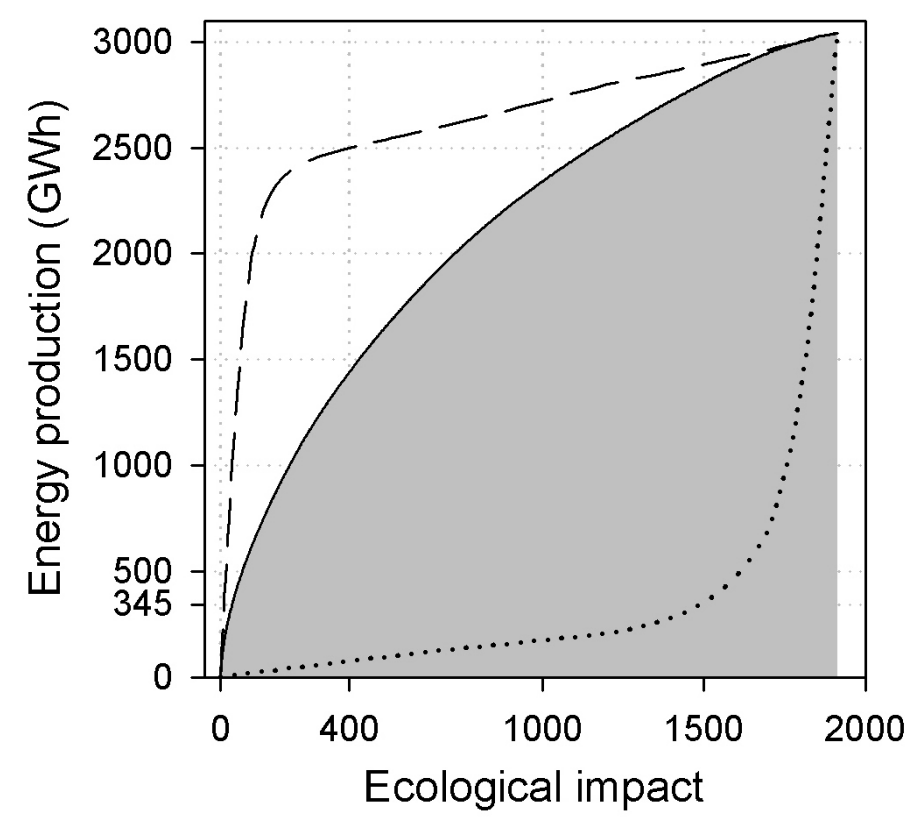

In addition to the discussion about the shape of the efficiency frontier, we compared its position with the current situation and found that efficiency gains can be achieved by reallocating WTs so that energy production can be increased without increasing the ecological impact, or the impact can be reduced without reducing energy production.

It should be noted, however, that we disregarded planning constraints that were considered to be relevant in the current allocation of WTs in the study region. We also neglected the site-specific private economic costs for land tenancy, foundation, and grid connection of WTs, etc., which also influence the optimal spatial allocation of WTs. In addition, this influence is reciprocal; i.e., the number, density, and dimension of wind farms and their distribution across the landscape affect the economic costs so that economies of scale and scope can be expected. However, since economic profits (benefits minus costs) from WTs are largely correlated with the local wind energy level, we can expect that many of our sites that were identified as Pareto-optimal with regards to wind power production would also be Pareto-optimal with regards to economic profits.

In addition to site-specific costs, the spatial reallocation of WTs would involve construction costs, transport costs, and potential fines associated with premature termination of lease contracts between WT operators and landowners, which would reduce the magnitude of the efficiency gains determined in our analysis. The consideration of monetary costs and benefits of wind power production will be the focus of future research.

Further simplifying assumptions were made in our study. We focused on the most relevant species, the red kite, and ignored other species that are less relevant but still need to be considered in real world landscape planning. Other species could be considered in our approach, although this would increase complexity because more criteria would have to be considered in the analysis and/or 
Fig. 7. Efficiency frontiers for different settlement distances. Settlement distances increase from top to bottom in steps of $100 \mathrm{~m}$ from $800 \mathrm{~m}$ to $1300 \mathrm{~m}$. Point i represents the current situation in the study region.

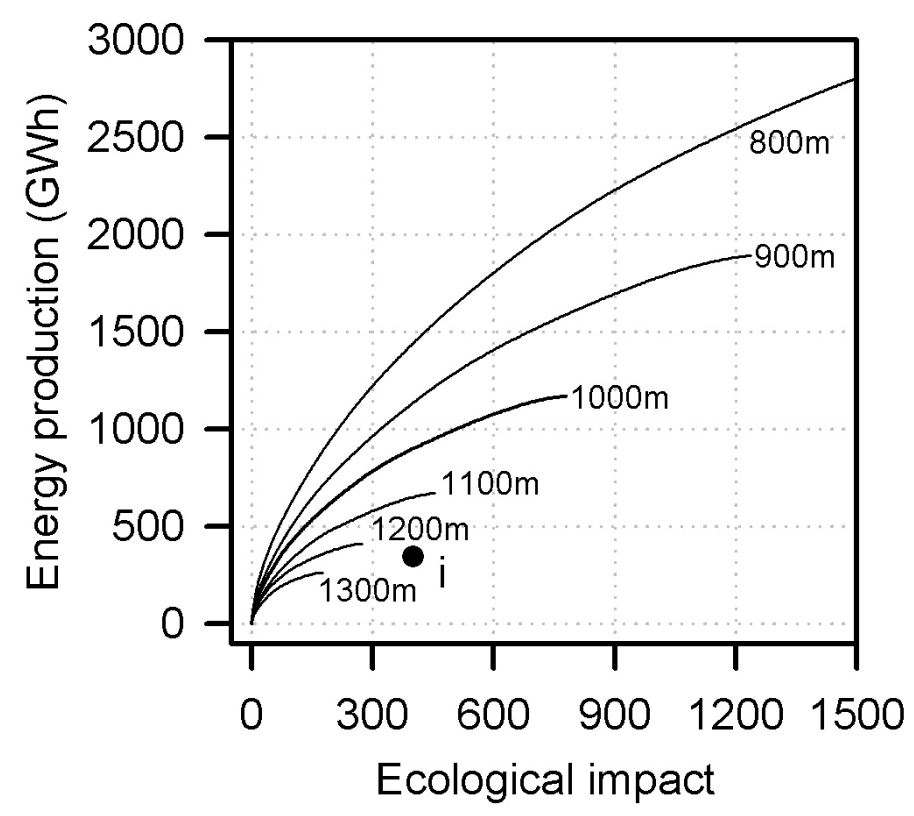

assumptions would have to be made on the aggregation of several species into one or a few joint impact criteria. Furthermore, we measured the ecological impact on an arbitrary scale, which was sufficient within the scope of our study but may be insufficient if the trade-offs are to be considered more concretely in making an actual planning decision. In that case, our impact index would have to be translated into a concrete parameter such as annual bird mortality or annual population decline. This would require the use of a behavioral model that simulates the foraging behavior of the species and quantitatively predicts the probability of a bird colliding with a WT at a particular location relative to the bird's aerie. Such a model might also take into consideration that some species are disturbed by WTs and avoid being around them. This reduces the amount of available habitat and poses another risk to biodiversity.

Nevertheless, our study demonstrates that it may be worthwhile to (i) reconsider some of the existing constraints and procedures of current landscape planning to open opportunities for efficiency gains in the context of wind power production, and (ii) use existing information such as species distribution maps and wind speed data more efficiently by employing formal decision making frameworks. Despite the negative impacts of WTs on some species, and given that wind power is a very emotional topic for many people, the pros and cons of WTs need to be assessed and valued carefully. Our study attempts to support this process.

Responses to this article can be read online at: http://www.ecologyandsociety.org/vol15/iss $2 /$ art10/ responses/ 
Fig. 8. Efficiency frontier. Impact value versus settlement distance. Upper line: energy production of $690 \mathrm{GWh}$; lower line: energy production of $345 \mathrm{GWh}$.

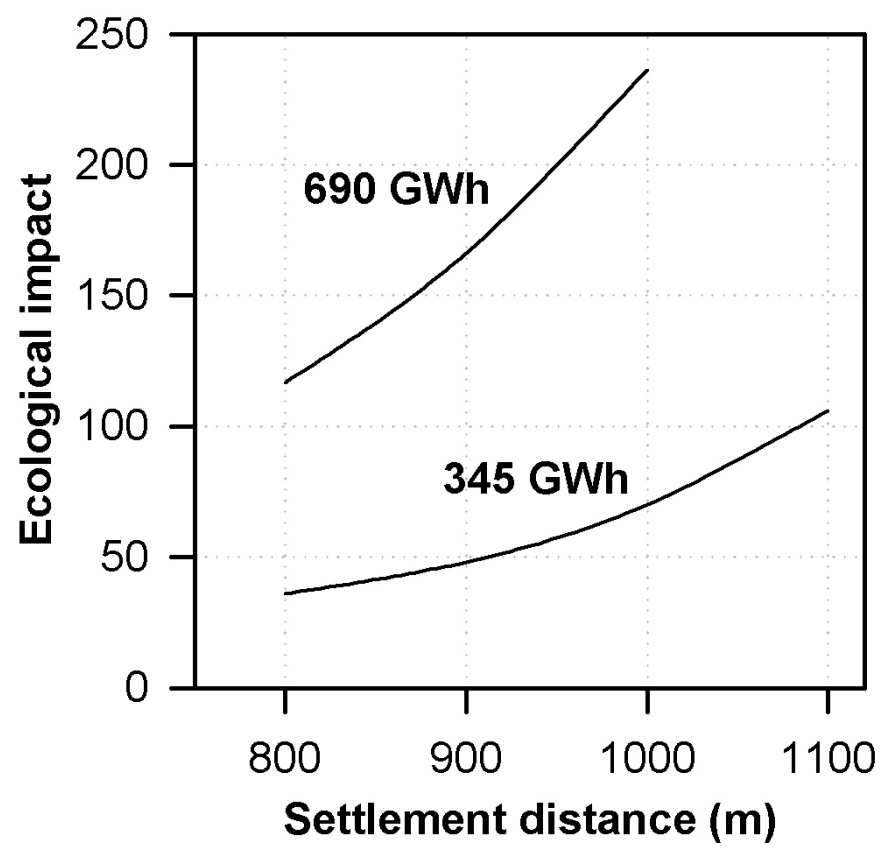

\section{Acknowledgments:}

We would like to thank RalfGuckel for programming the Monte Carlo Simulation to allocate potential wind turbine sites within the suitability space, and Ralf Seppelt and Cornelia Ohl for providing valuable comments on the manuscript. We are grateful for the helpful comments of the two anonymous reviewers. The authors wish to thank the Ministry for Education and Research forfunding the research project "Conflicts of interest over wind power” [Nachhaltige Landnutzung im Spannungsfeld umweltpolitisch konfligierender Zielsetzungen am Beispiel der Windenergiegewinnung] (Grant No. 01UN0601A, B) as a part of the Fona Programme "Economics for Sustainability [Wirtschaftswissenschaften für Nachhaltigkeit] (WIN)". This work was further supported by the Helmholtz Impulse and Networking Fund through the Helmholtz Interdisciplinary Graduate School for Environmental Research (HIGRADE).

\section{LITERATURE CITED}

Bettinger, P., K. Boston, Y.-H. Kim, and J. Zhu. 2007. Landscape-level optimization using tabu search and stand density-related forest management prescriptions. European Journal of Operational Research 176(2):1265-1282.

Bettinger, P., K. Boston, and J. Sessions. 2008. Simulated annealing. Pages 3255-3261 in S. E. Jorgensen and B. Faith, editors. Encyclopedia of ecology. doi:10.1016/B978-008045405-4.00167-1.

BfN - Bundesamt für Naturschutz. 2008. (internal report) Naturschutzrelevanz raumbedeutsamer Auswirkungen der Energiewende. (transl. Federal Agency of Nature Conservation (2008 unpublished) Relevance to nature conservation concerns of large scale effects of renewable energy evolution.

Bishop, I. D. 2002. Determination of thresholds of visual impact: the case of wind turbines. Environment and Planning B: Planning and Design 29:707-718. 
BirdLife International. 2009. Red kite Milvus milvus. BirdLife species factsheet. [online] URL: http://www.birdlife.org/datazone/species/index.html? action=SpcHTMDetails . asp \&sid=3353\&m=0.

Bladt, J., N. Strange, J. Abildtrup, J. C. Svenning, and F. Skov. 2009. Conservation efficiency of geopolitical coordination in Europe. Journal for Nature Conservation 17:72-86.

Bright, J., R. Langston, R. Bullman, R. Evans, S. Gardner, and J. Pearce-Higgins. 2008. Map of bird sensitivities to wind farms in Scotland: a tool to aid planning and conservation. Biological Conservation 141:2342-2356.

Brown K., and E. Corbera. 2003. A multi-criteria assessment framework for carbon-mitigation projects: putting "development" in the centre of decision-making. Tyndall Centre for Climate Change Research Working Paper 29.

BMU - Bundesministerium für Umwelt, Naturschutz und Reaktorsicherheit. 2008. Lead study 2008 - Further development of the "Strategy to increase the use of renewable energies" within the context of the current climate protection goals of Germany and Europe. Berlin, Germany.

Carmen, A., T. Sibille, V. A. Cloquell-Ballester, V. A. Cloquell-Ballester, and R. Darton. 2009. Development and validation of a multicriteria indicator for the assessment of objective aesthetic impact of wind farms. Renewable and Sustainable Energy Reviews 13:40-66.

Calkin, D. E., C. A. Montgomery, N. H. Schumaker, S. Polasky, J. L. Arthur, and D. J. Nalle. 2002. Developing a production possibility set of wildlife species persistence and timber harvest value. Canadian Journal of Forest Research 32:1329-1342.

CBD - Center for Biological Diversity. 2009. Fact sheet on Altamont Pass bird kills. Centre for Biological Diversity, San Francisco Bay Area Office, 1095 Market Street, Suite 511, San Francisco, California, USA. [online] URL: http://w ww.biologicaldiversity.org/campaigns/ protecting birds of prey at altamont pass/pdfs/factsheet. pdf.

Dantzig, G. B. 1963. Linear programming and extensions. Princeton University Press, Princeton,
New Jersey, USA.

Dürr, T. 2008. Vogelverluste an Windenergieanlagen in Deutschland, Daten aus der zentralen Fundkartei der Staatlichen Vogelschutzwarte im Landesumweltamt Brandenburg Stand September 2008. (transl. Bird losses on wind power engines in Germany, data from the central finding card index of the state ornithological station in the environmental authority of Brandenburg. state September, 2008). [online] URL: http://www.mugv.brandenburg.de/cms/ media.php/lbml.a.2334.de/wka vogel.xls.

Ehsan, H. F., R. L. Raab, G. T. Ulleberg, and K. Alsharif. 2009. Global warming and environmental production efficiency ranking of the Kyoto Protocol nations. Journal of Environmental Management 90:1178-1183.

ENERCON. 2008. Wind turbines product overview. [online] URL: http://www.enercon.de/w ww/en/broschueren.nsf/vwwebAnzeige/15686F537 B20CA13C125719400261D37/\$FILE/ ENE Produktuebersicht eng.pdf.

Glutz von Blotzheim, U., K. M. Bauer, and E. Bezzel. 1989. Handbuch der Vögel Mitteleuropas, Band 4. Falconiformes. Second edition. AulaVerlag, Wiesbaden, Germany.

Hajkowicz S., R. Spencer, A. Higgins, and $O$. Marinoni. 2008. Evaluating water quality investments using cost utility analysis. Journal of Environmental Management 88:1601-1610.

Hau, E. 2006. Fundamentals, technology, application economics. Springer Berlin, Heidelberg, Germany.

Hötker, H., K. M. Thomsen, and H. Jeromin. 2006. Impacts on biodiversity of exploitation of renewable energy sources: the example of birds and bats - facts, gaps in knowledge, demands for further research, and ornithological guidelines for the development of renewable energy exploitation. Michael-Otto-Institut im NABU, Bergenhusen. [online] URL: http://www.batsandwind.org/pdf/im pacts $\% 20$ on $\% 20$ biodiversity $\% 20$ of $\% 20$ renewable $\%$ 20energy.pdf.

Hunt, G. 2002. Golden Eagles in a perilous landscape: predicting the effects of mitigation for wind turbine blade-strike mortality. California Energy Commission University of California, Santa 
Cruz. Contract No. 500-97-4033. [online] URL:

http://www.energy.ca.gov/reports/2002-11-04 500 -02-043F.PDF.

Huth, A., M. Drechsler, and P. Köhler. 2005. Using multicriteria decision analysis and a forest growth model to assess impacts of tree harvesting in Dipterocarp lowland rain forests. Forest Ecology and Management 207:215-232.

Kiker, G. A., T. S. Bridges, A. Varghese, T. P. Seager, and I. Linkov. 2005. Application of multicriteria decision analysis in environmental decision making. Integrated Environmental Assessment and Management 1:95-108.

Kirkpatrick, S., C. D. Gelatt, and M. P. Vecchi. 1983. Optimization by simulated annealing. Science 220 (4598):671-680.

Langston, R. H. W., and J. D. Pullan. 2003. Windfarms and birds: an analysis of the effects of wind farms on birds, and guidance on environmental assessment criteria and site selection issues. Report T-PVS/Inf (2003) 12, by BirdLife International to the Council of Europe, Bern Convention on the Conservation of European Wildlife and Natural Habitats. RSPB/BirdLife in the UK. [online] URL: http://www.birdlife.org/eu/pdfs/BirdLife Bern windfarms. pdf.

LANUV NRW - Landesamt für Natur, Umwelt und Verbraucherschutz Nordrhein-Westfahlen. 2002. Material 63 - Windenergieanlagen und Immissionsschutz. [online] URL: http://www.lanuv. nrw.de/veroeffentlichungen/materialien/mat63/ mat63 web.pdf.

Lowitz, M. 2008. Altamont Pass, California. [online] URL:

http://www.eoearth.org/article/Altamont_Pass,_California

Mammen, U., and T. Dürr. 2006. Rotmilane und Windkraftanlagen- Konflikt oder Übertreibung? APUS Vereinszeitschrift Ornithologenverband Sachsen-Anhalt e.V. Heft 1/2006 Band 13.

Mebs, T., and D. Schmidt. 2006. Die Greifvögel Europas, Nordafrikas und Vorderasiens. FranckKosmos Verlag, Stuttgart, Germany.

Meyer, B. C., and R. Grabaum. 2008. MULBO Model framework for multicritieria landscape assessment and optimisation - a support system for spatial land use decision. Landscape Research 33 (2):155-179.

Meyerhoff, J., C. Ohl, and V. Hartje. 2008. Präferenzen für die Gestaltung der Windkraft in der Landschaft-Ergebnisse einer Online-Befragung in Deutschland. Working Paper on Management in Environmental Planning No. 24/2008. Technischen Universität Berlin, Berlin, Germany.

Moffett, A., and S. Sarkar. 2006. Incorporating multiple criteria into the design of conservation area networks: a minireview with recommendations. Diversity and Distributions 12:125-137.

Möller, B. 2006. Changing wind-power landscapes: regional assessment of visual impact on land use and population in Northern Jutland, Denmark. Applied Energy 83:477-494.

Nachtigall, W. 2008. Der Rotmilan (Milvus milvus, L. 1758) in Sachsen und Südbrandenburg Untersuchungen $\mathrm{zu}$ Verbreitung und Ökologie. Dissertation, Martin-Luther-Universität Halle Wittenberg. [online] URL:

http://sundoc.bibliothek.uni-halle.de/dissonline/08/08H218/index.htm.

Nalle, D. J., C. A. Montgomery, J. L. Arthur, S. Polasky, and N. H Schumaker. 2004. Modelling joint production of wildlife and timber. Journal of Environmental Economics and Management 48: 997-1017.

Öhmann, K. and L. O. Eriksson. 2002. Allowing for spatial consideration in long-term forest planning by linking linear programming with simulated annealing. Forest Ecology and Management 161:221-230.

Polasky, S., E. Nelson, J. Camm, B. Csuti, P. Fackler, E. Lonsdorf, C. Montgomery, D. White, J. Arthur, B. Graber-Yonts, R. Haight, J. Kagan, A. Starfield, and C. Tobalske. 2008. Where to put things? Spatial land management to sustain biodiversity and economic returns. Biological Conservation 141:1505-1524.

RPG ABW - Regionale Planungsgemeinschaft Anhalt-Bitterfeld-Wittenberg. 2007.

Raumordnungsbericht 2007. [online] URL:

http://www.regionale-planungsgemeinschaft-anhaltbitterfeld-wittenberg.de/aktuell/V071120 raumord nungsbericht2007 abw151107.pdf. 
RPV WS - Regionaler Planungsverband Westsachsen. 2008. Regional plan 2008.

Regionale Planungsstelle Leipzig Bautzner Str. 67 04347 Leipzig, Germany.

Reichenbach M., K. Handke, and F. Sinning. 2004. Der Stand des Wissens zur Empfindlichkeit von Vogelarten gegenüber Störungswirkungen von Windenergieanlagen. Bremer Beiträge für Naturkunde und Naturschutz 7:229-243.

Schrijver A. 1998. Theory of linear and integer programming. John Wiley \& Sons, Chichester, UK.

Tsoutsos T., A. Tsouchlaraki, M. Tsiropoulos, and M. Serpetsidakis. 2009. Visual impact evaluation of a wind park in a Greek island. Applied Energy 86:546-553.

TA Lärm. 1998. Technische Anleitung zum Schutz gegen Lärm [neue Fassung] Sechste Allgemeine Verwaltungsvorschrift zum Bundes-Immissionsschutzgesetz (TA Lärm) vom 26. August 1998 (GMB1. Nr. 26 vom 28.08.1998 S. 503).

Westphal, M. I., S. A. Field, and H. P. Possingham. 2007. Optimizing landscape configuration: a case study of woodland birds in the Mount Lofty Ranges, South Australia. Landscape and Urban Planning 81:56-66.

Wizelius, T. 2007. Developing wind power projects - theory and practice. Earthscan, London Sterling, UK. 